\title{
Comparison of Methods for Predicting Shear-Wave Velocities of Unconsolidated Shallow Sediments in the Gulf of Mexico
}

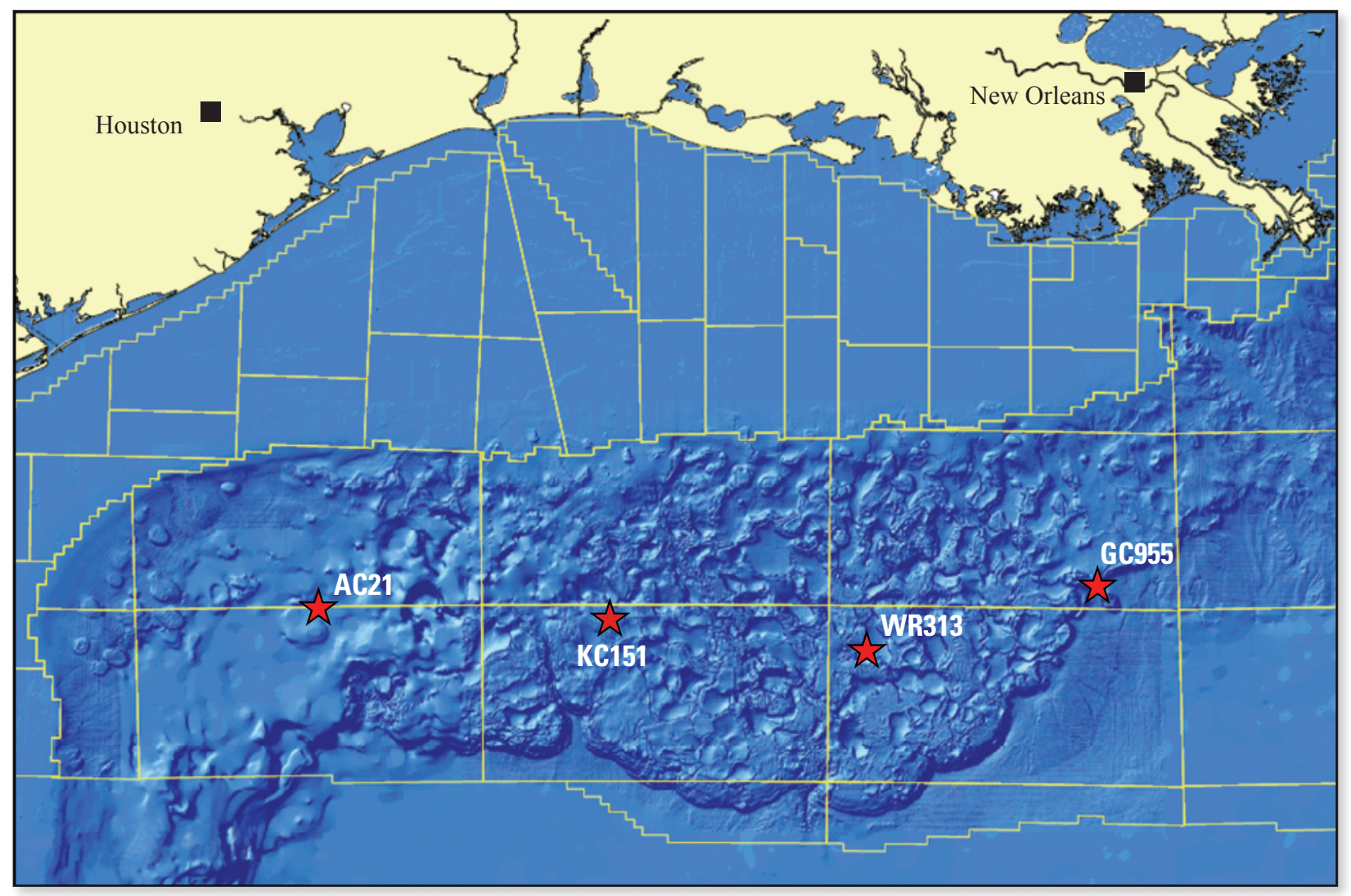

Scientific Investigations Report 2013-5141 



\section{Comparison of Methods for Predicting Shear-Wave Velocities of Unconsolidated Shallow Sediments in the Gulf of Mexico}

By Myung W. Lee

Scientific Investigations Report 2013-5141 


\title{
U.S. Department of the Interior SALLY JEWELL, Secretary
}

\section{U.S. Geological Survey Suzette M. Kimball, Acting Director}

\author{
U.S. Geological Survey, Reston, Virginia: 2013
}

For more information on the USGS - the Federal source for science about the Earth, its natural and living resources, natural hazards, and the environment, visit http://Www.usgs.gov or call 1-888-ASK-USGS.

For an overview of USGS information products, including maps, imagery, and publications, visit http://Www.usgs.gov/pubprod

To order this and other USGS information products, visit http://store.usgs.gov

Any use of trade, firm, or product names is for descriptive purposes only and does not imply endorsement by the U.S. Government.

Although this information product, for the most part, is in the public domain, it also may contain copyrighted materials as noted in the text. Permission to reproduce copyrighted items must be secured from the copyright owner.

Suggested citation:

Lee, M.W., 2013, Shear wave velocities of unconsolidated shallow sediments in the Gulf of Mexico: U.S. Geological Survey Scientific Investigations Report 2013-5141, 11 p., http://pubs.usgs.gov/sir/2013/5141/. 


\section{Acknowledgments}

I thank J.J. Miller and W.F. Agena for their many helpful comments and suggestions and T.S. Collett for his continuous support of this investigation. This work was funded by the U.S. Department of Energy and the Energy Resources Program of the U.S. Geological Survey. Data used in this paper were provided by the U.S. Department of Energy-sponsored Gulf of Mexico Gas Hydrate Joint Industry Project Leg II.

\section{Contents}

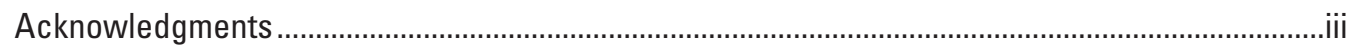

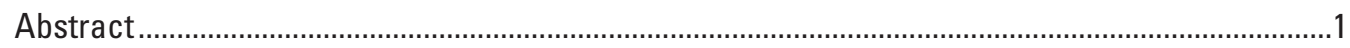

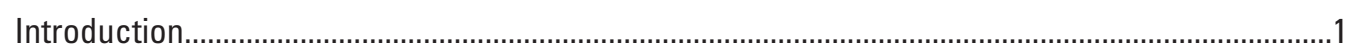

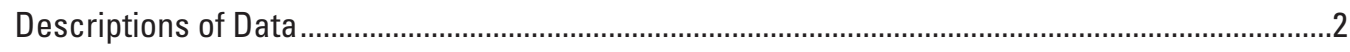

Biot-Gassmann Theory with Consolidation Parameter ....................................................................

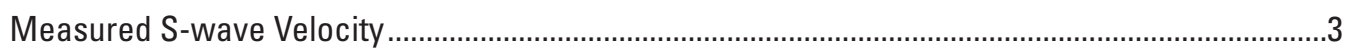

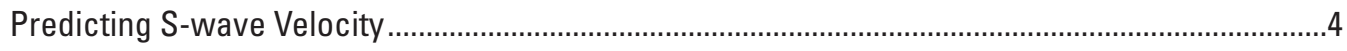

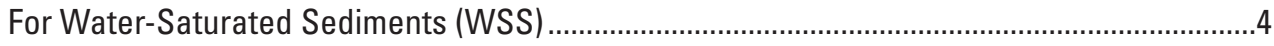

For Gas Hydrate-Bearing Sediments (GHBS) .....................................................................

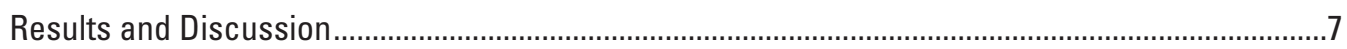

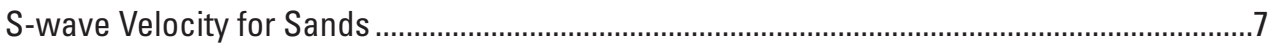

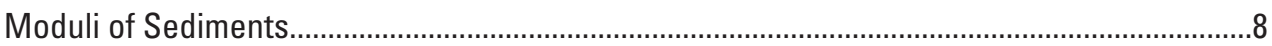

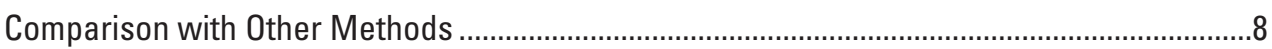

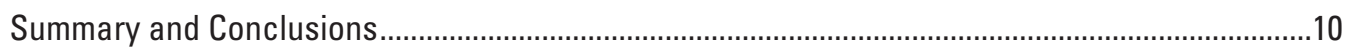

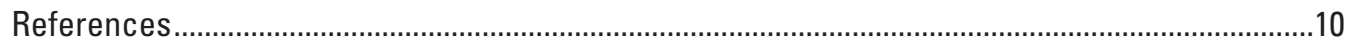

\section{Figures}

1. Map showing locations of sites drilled during the Joint Industry Project Leg II Expedition and the KC151 site, Gulf of Mexico

2. Graph showing a relation between $P$ - and $S$-wave velocities measured using SonicScope acoustic logging tool at six wells acquired during the Joint Industry Project Leg II Expedition in the Gulf of Mexico

3. Graph showing predicted S-wave velocities at the AC21-A well using the empirical equation and the Biot-Gassman theory (BGT) with a consolidation parameter (equations 1 through 4)

4. Graphs showing predicted and measured SonicScope S-wave velocities at the WR313-H well, with S-wave velocities measured by Lee and others (2008) for the reconstituted sediment acquired at the Keathley Canyon 151-2 well (KC151-2).............5

5. Graph showing predicted and measured SonicScope S-wave velocities at the GC955-H wellwith gas hydrate saturations estimated from the P-wave velocity............6

6. Measured and modified porosity and P-wave velocity at the GC955-H well....................7

7. Graph showing estimated bulk and shear moduli of sediments at the GC995-H well......9

8. Comparisons of predicted and measured SonicScope S-wave velocities in the Gulf of Mexico 



\title{
Comparison of Methods for Predicting Shear-Wave Velocities of Unconsolidated Shallow Sediments in the Gulf of Mexico
}

\author{
By Myung W. Lee
}

\section{Abstract}

Accurate shear-wave velocities for shallow sediments are important for a variety of seismic applications such as inversion and amplitude versus offset analysis. During the U.S. Department of Energy-sponsored Gas Hydrate Joint Industry Project Leg II, shear-wave velocities were measured at six wells in the Gulf of Mexico using the logging-while-drilling SonicScope acoustic tool. Because the tool measurement point was only 35 feet from the drill bit, the adverse effect of the borehole condition, which is severe for the shallow unconsolidated sediments in the Gulf of Mexico, was minimized and accurate shear-wave velocities of unconsolidated sediments were measured. Measured shear-wave velocities were compared with the shear-wave velocities predicted from the compressional-wave velocities using empirical formulas and the rock physics models based on the Biot-Gassmann theory, and the effectiveness of the two prediction methods was evaluated. Although the empirical equation derived from measured shear-wave data is accurate for predicting shearwave velocities for depths greater than 500 feet in these wells, the three-phase Biot-Gassmann-theory -based theory appears to be optimum for predicting shear-wave velocities for shallow unconsolidated sediments in the Gulf of Mexico.

\section{Introduction}

Shear-wave (S-wave) velocities are essential in seismic modeling such as amplitude versus offset, multicomponent seismic analysis, and seismic inversion. Also, S-wave velocities are important in estimating mechanical properties of unconsolidated gas hydrate-bearing sediments (GHBS), which plays a key role in designing production test wells for the gas hydrates. Therefore, predicting, theoretically or empirically, the S-wave velocities from the compressional-wave (P-wave) velocities is needed, because $\mathrm{S}$-wave velocities are rarely measured. Particularly for the study of GHBS, S-wave velocities of unconsolidated sediments at low effective pressure help to develop a more effective elastic inversion method (Lee, 2006a).
Castagna and others (1985) published an empirical relationship between $\mathrm{S}$-wave velocities and the P-wave velocities for water-saturated clastic silicates, known as the mudrock line. The mudrock line can be used to derive S-wave velocities when other alternative relations are unavailable, but it underestimates S-wave velocity for unconsolidated sediment (Wang, 2000). A similar result is given by Han and others (1986). Wang (2000) introduced an empirical equation of predicting S-wave velocities, which depends on the bulk density of the saturated rock and the pore fluid modulus as well as the P-wave velocity. In contrast to the $\mathrm{S}$-wave velocities predicted from Castagna and others (1985) or Han and others (1986), Wang's empirical method is valid for fluids other than water in the pore space.

Greenberg and Castagna (1992) proposed a semiphysical model based on the Biot-Gassmann theory (BGT) under the assumptions that there exists a robust relationship between P-and S-wave velocities and that nearly linear mixing laws for solid rock constituents are valid. By using laboratory measurements and well logs, they demonstrated that the precision and accuracy of S-wave velocity prediction are 9 percent and 3 percent, respectively.

$\mathrm{Xu}$ and White (1996) predicted S-wave velocities combining the Kuster and Toksöz theory (1974) and the differential effective medium theory (Cheng and Toksöz, 1979) and using pore-aspect ratios to characterize the compliance of the sand and clay components. They applied their method to the velocities measured at a differential pressure of 5 megaPascal (MPa) by Han and others (1986) and showed that the predicted $\mathrm{S}$-wave velocities agreed well with the measured velocities (slight overestimation).

Jørstad and others (1999) compared S-wave velocities predicted from the inclusion-based effective medium theory to those estimated from empirical regressions at a North Sea reservoir. While effective medium theories are more complex than the statistical regression methods, they have the advantage of incorporating the effect of clay and pore geometry directly into the formulation. But Jørstad and others (1999) concluded that empirical methods are as effective as the inclusion-based methods and are more easily applicable.

Lee (2006b) predicted S-wave velocities using the BGT with a correction term, and Lee (2006c, 2010) used BGT with consolidation parameters to predict $\mathrm{S}$-wave velocity from the 
P-wave velocity and porosity. Because of the lack of S-wave velocities measured at effective pressure less than about $5 \mathrm{MPa}$, the effectiveness of each method for the shallow sediments was not rigorously investigated.

In 2009, the U.S. Department of Energy-sponsored Gas Hydrate Joint Industry Project Leg II (JIP Leg II) conducted logging-while-drilling (LWD) operations at three sites (Walker Ridge, Green Canyon, and Alaminos Canyon) in the northern Gulf of Mexico (fig. 1; Boswell and others, 2009). These locations were identified primarily from 3-D seismic data to test geological and geophysical interpretation methods to prospect for gas hydrate-bearing sand reservoirs (Hutchinson and others, 2009; Shedd and others, 2009). During this expedition, a suite of LWD well logs, including S-wave velocities at shallow depths, was acquired.

The purpose of this paper is to present the LWD logging data acquired during JIP Leg II, along with laboratory data by Zimmer (2003) and Lee and others (2008) used to investigate and compare the prediction methods for S-wave velocities applicable at low effective pressure of unconsolidated shallow sediments. This paper also presents an effective method for predicting S-wave velocities of GHBS, which can be used to estimate the dynamic moduli of GHBS.

\section{Descriptions of Data}

The S-wave velocities were acquired using SonicScope (Schlumberger's newer generation acoustic tool, Mrozewski and others, 2009) at the Walker Ridge well site (WR 313-H well located at a water depth of 6,450 feet (ft) or 1,966 meters (m)), the Alaminos Canyon site (AC21-A well located at a water depth of 4,889 ft or 1,490 m, and AC21-B located at a water depth of 4,883 ft or 1,488 m), and the Green Canyon site (GC 955-H well located at a water depth of $6,670 \mathrm{ft}$ or 2,033 $\mathrm{m}, \mathrm{GC} 955-\mathrm{I}$ located at the water depth of $6,822 \mathrm{ft}$ or 2,079 $\mathrm{m}$, and GC955-Q located at a water depth of $6,516 \mathrm{ft}$ or 1,986 $\mathrm{m})$ (fig. 1). The measurement point on the tool was located $35.45 \mathrm{ft}(10.8 \mathrm{~m})$ from the drill bit, and it was the closest tool in the LWD logging assembly. Because of the short distance from the drill bit, the adverse effects of the borehole such as washout were minimized for the SonicScope data. The P-wave velocities were estimated from the waveform in the frequency range of 2.5-4.5 kiloherz (KHz), and S-wave velocities were processed using frequencies less than $3 \mathrm{KHz}$. Although highquality P-wave velocities were acquired throughout the logged interval (Guerin and others, 2009), the S-wave velocities were only interpretable in limited depth ranges due to the low signalto-noise ratio of the shear arrivals. In spite of this limitation of the S-wave velocity, the LWD S-wave data provided a critical dataset to be used to model S-wave velocities of shallow sediments in the Gulf of Mexico (GOM).

The shallowest sediment measured by SonicScope was at the AC21-A well at a depth of 468 feet below sea floor (fbsf), which corresponds to an effective pressure of about $1.5 \mathrm{MPa}$. To constrain S-wave velocities for effective pressure less than about 1.5 MPa, S-wave velocities measured for reconstituted sediments at Keathley Canyon lease block 151 (KC151) at $4,369 \mathrm{ft}(1,323 \mathrm{~m})$ water depth, in the northern Gulf of Mexico

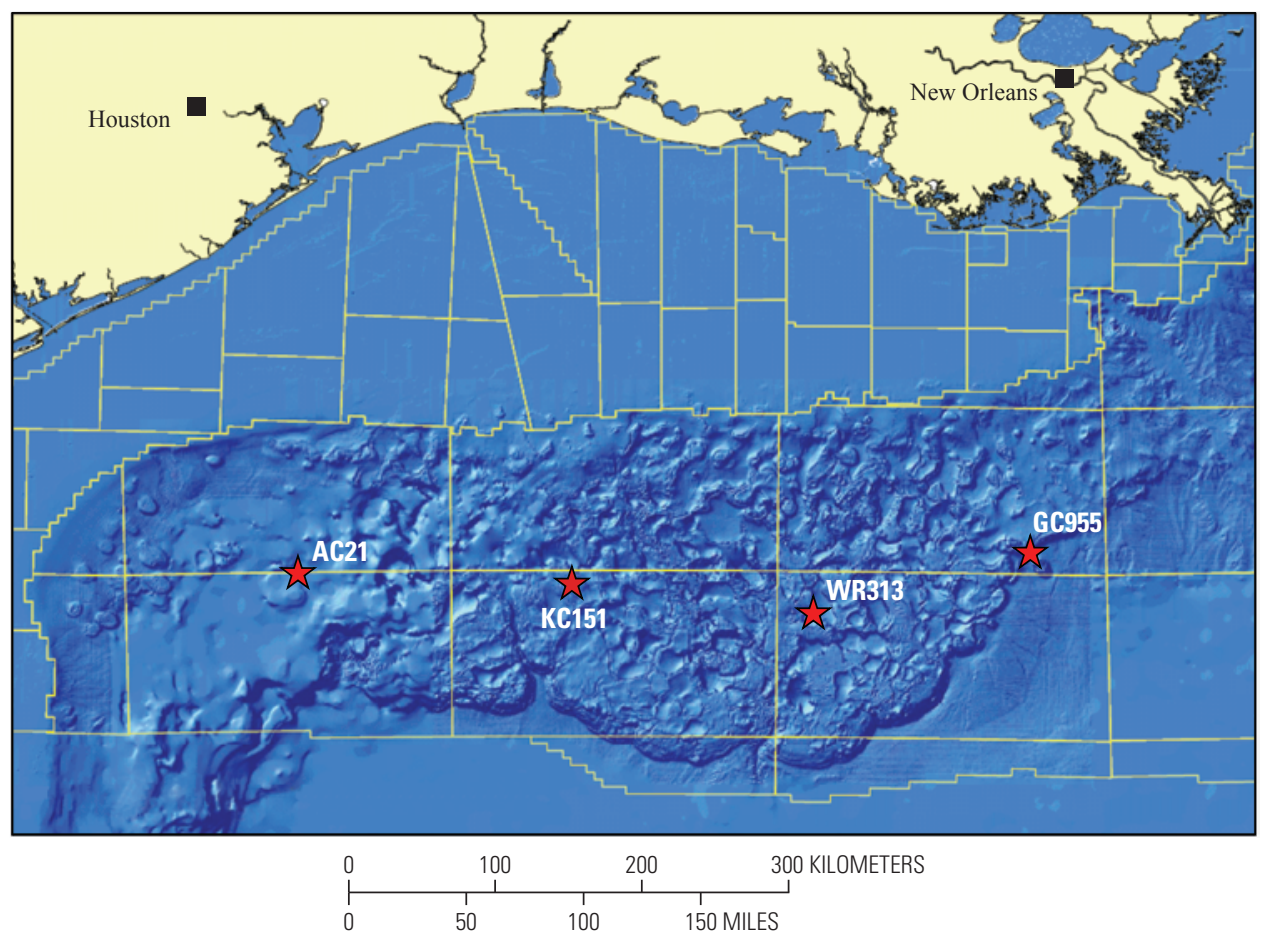

Figure 1. Locations of sites drilled during the Joint Industry Project Leg II Expedition and the KC151 site, Gulf of Mexico (modified from Boswell and others, 2009). WR, Walker Ridge; AC, Alaminos Canyon; GC, Green Canyon; KC, Keathley Canyon. 
between WC and AC sites (fig. 1), were used. Sediments in this site are classified as inorganic clays with high plasticity (Yun and others, 2006). Detailed descriptions of core samples collected at KC151 are shown in Lee and others (2008) and Yun and others (2006). Only S-wave velocities at various effective pressures less than $2.3 \mathrm{MPa}$ were measured with the frequency of 5-70 KHz for the reconstituted sediments (Lee and Ruppel, 2008) and S-wave velocities measured during the loading cycle were used in this paper.

\section{Biot-Gassmann Theory with Consolidation Parameter}

The P-wave $(V p)$ velocity and the shear-wave velocities $(V s)$ of water-saturated sediment can be written as:

$$
V_{p}=\sqrt{\frac{k+4 \mu / 3}{\rho_{b}}} \text { and } \quad V_{s}=\sqrt{\frac{\mu}{\rho_{b}}}
$$

where

$k$ and $\mu$ are bulk and shear moduli of the sediment, $\rho_{b}$ is the bulk density of sediment given by $\rho_{b}=\rho_{s}(1-\phi)+\rho_{w} \phi$, and

subscripts $s$ and $w$ refer to sediment grains and water, respectively, and

$\phi$ is sediment porosity.

According to the rock physics model based on BGT, the bulk modulus of the sediment is given by:

$$
k=K_{s}\left(1-\beta_{p}\right)+\beta_{p}^{2} K_{a v}
$$

with

$$
\frac{1}{K_{a v}}=\frac{\left(\beta_{p}-\phi\right)}{K_{s}}+\frac{\phi}{K_{w}}
$$

and the shear modulus is given by (Lee, 2005)

$$
\mu=\mu_{s}\left(1-\beta_{s}\right)
$$

where

$\beta_{p}$ and $\beta_{s}$ are appropriate Biot coefficients for bulk and shear moduli,

$\mathrm{K}_{\mathrm{s}}$ and $\mu_{\mathrm{s}}$ are bulk and shear moduli of grains, and

$\mathrm{K}_{\mathrm{w}}$ is the bulk modulus of pore water.

The Biot coefficients shown in equations 2 and 3 can be written as (Lee, 2005):

$$
\begin{gathered}
\beta_{p}=\frac{\phi(1+\alpha)}{(1+\alpha \phi)} \quad \beta_{s}=\frac{\phi(1+\gamma \alpha)}{(1+\gamma \alpha \phi)}, \\
\text { with } \gamma=\frac{1+2 \alpha}{1+\alpha}
\end{gathered}
$$

where $\alpha$ is the consolidation parameter (Pride, 2005; Lee, 2005). Pride (2005) used a constant value for $\gamma$, whereas Lee (2005) used $\gamma$ as a function of the consolidation parameter. Lee (2005) shows that using $\gamma$ as a function of $\alpha$ yields more accurate velocities, particularly for unconsolidated sediments. The consolidation parameter $\alpha$ can be estimated from the P-wave velocity and porosity with the grain properties as shown in Lee (2006c).

\section{Measured S-wave Velocity}

Figure 2 shows a relation between $\mathrm{P}$ - and S-wave velocities measured by the SonicScope at 6 wells in the GOM. Most of the data points fall within uncertainties of the data scattering. A least squares fit (LSF) to the data shown in figure 2 is given by:

$$
V_{s}=0.59 V_{p}-0.6
$$

with a correlation coefficient of 0.88 .

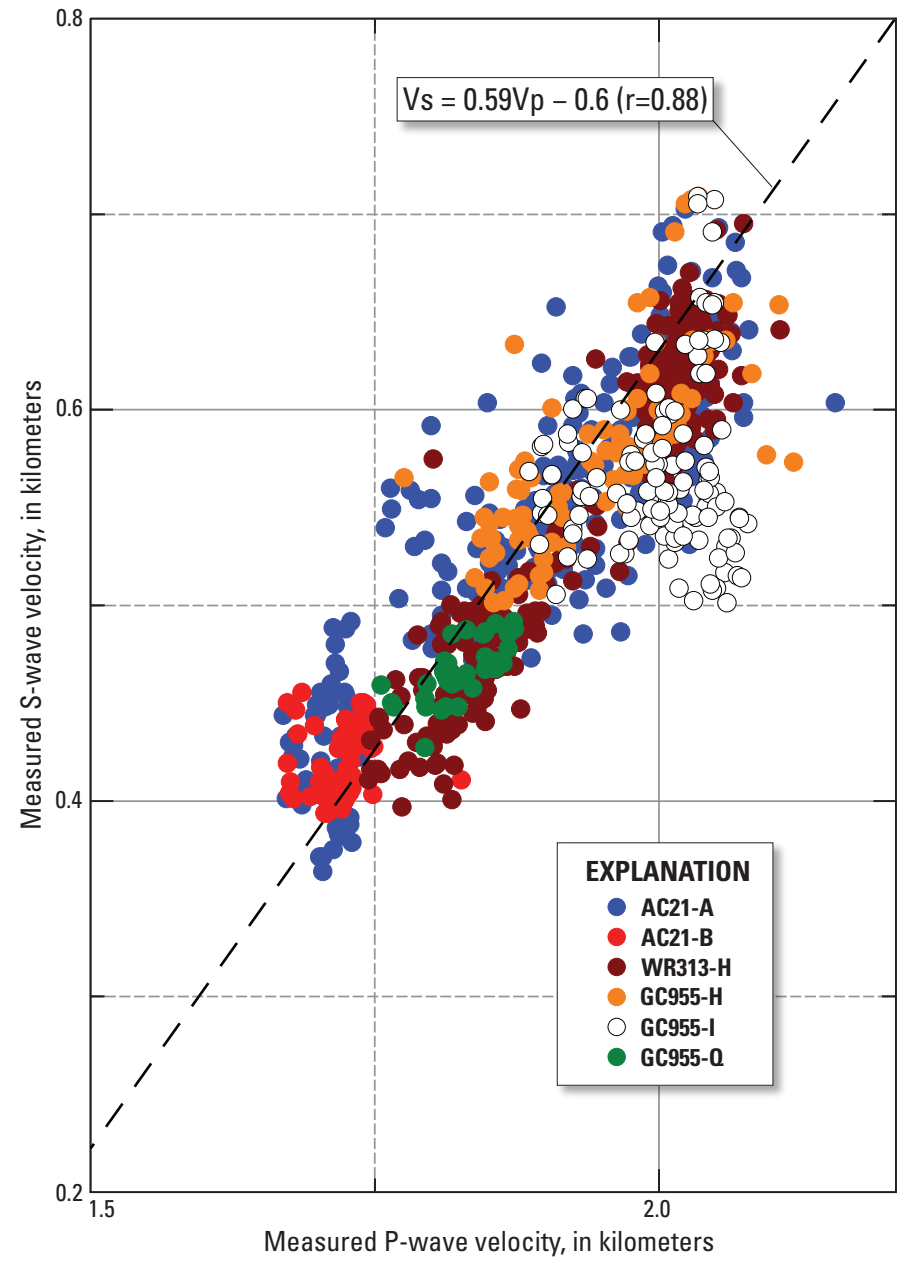

Figure 2. Relation between $\mathrm{P}$ - and S-wave velocities measured using Sonic Scope acoustic logging tool at six wells acquired during the Joint Industry Project Leg II Expedition in the Gulf of Mexico. $V_{p^{\prime}}$ P-wave velocity; $V_{s^{\prime}} S$-wave velocity; $r$, correlation coefficient; WR, Walker Ridge; AC, Alaminos Canyon; GC, Green Canyon; KC, Keathley Canyon. 


\section{Predicting S-wave Velocity}

A general description of predicting S-wave velocity of the water-saturated sediment (WSS) at low effective pressure is described in Lee (2010). This section of the paper presents methods of predicting S-wave velocities for WSS and GHBS from the P-wave velocities measured at low frequencies less than or equal to the logging frequencies. If the P-wave velocities were measured at higher frequencies (greater than about $200 \mathrm{KHz}$ ), the velocity dispersion effect should be accounted for and S-wave velocities at low effective pressure should be accurately predicted (Lee, 2010).

\section{For Water-Saturated Sediments (WSS)}

Figure 3 shows the predicted S-wave velocities at the $\mathrm{AC} 21-\mathrm{A}$ well using the empirical relation given in equation 5 and using the BGT as outlined in Lee (2006c). The average measured S-wave velocities at the AC21-A well is $0.541 \pm 0.08$ kilometers per second $(\mathrm{km} / \mathrm{s})$, whereas the predicted average S-wave velocities from the empirical and BGT are $0.529 \pm 0.09 \mathrm{~km} / \mathrm{s}$ and $0.546 \pm 0.11 \mathrm{~km} / \mathrm{s}$, respectively. The empirical equation slightly underestimates the S-wave velocities, whereas the BGT slightly overestimates S-wave velocities. However, the difference is not significant and both methods are appropriate for predicting the S-wave velocity at the AC21-A well.

Figure $4 A$ shows the predicted $\mathrm{S}$-wave velocities with depth at the WR313-H well using the empirical equation along with measured SonicScope S-wave data and S-wave velocities of reconstituted sediments by Lee and others (2008). The predicted S-wave velocities using the empirical equation agree well with measured SonicScope S-wave velocities. However, the empirical equation slightly overestimates the $\mathrm{S}$-wave velocities when the water depth is less than about $200 \mathrm{ft}$, or an effective pressure of about $0.6 \mathrm{MPa}$.

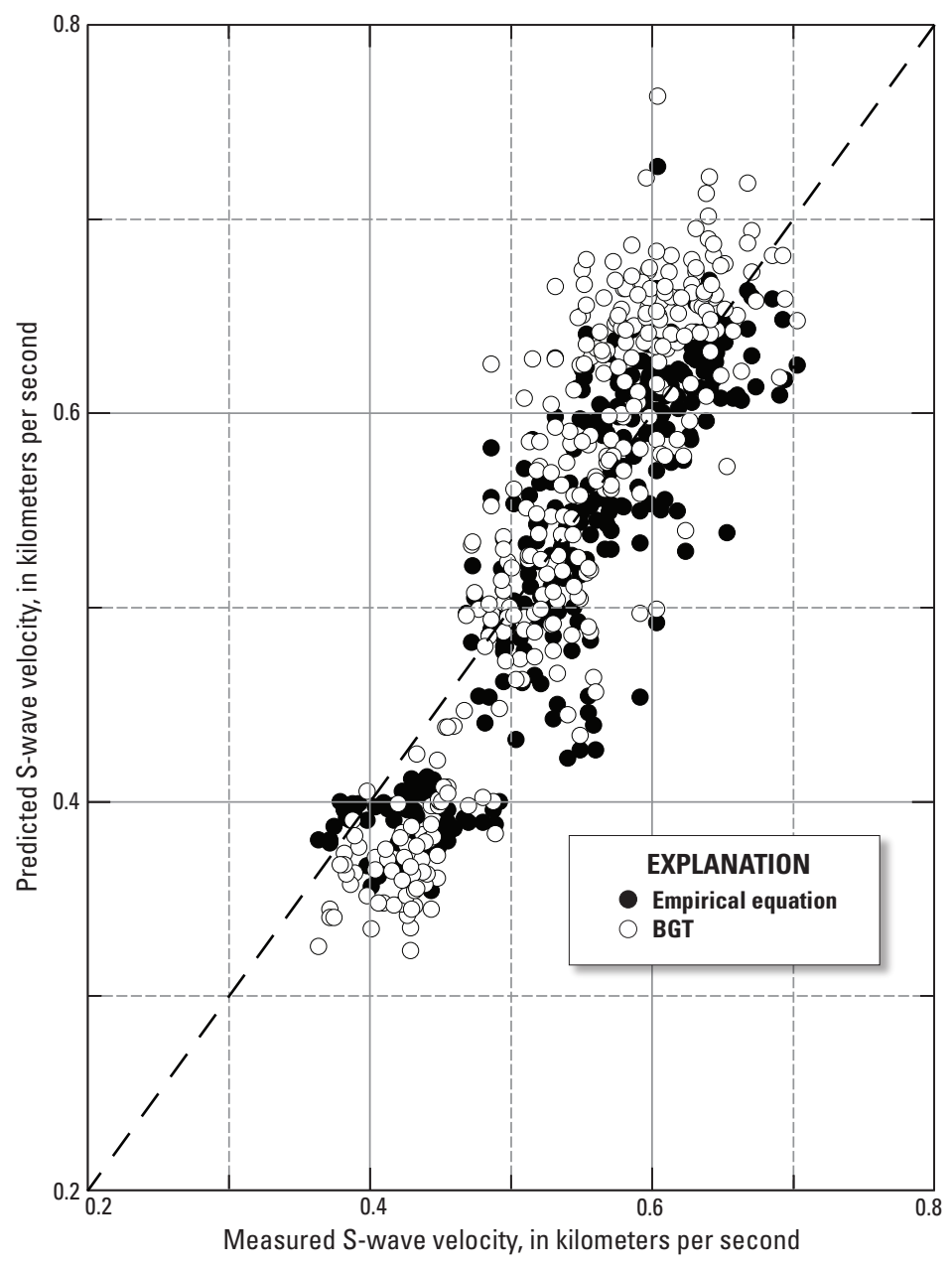

Figure 3. Predicted S-wave velocities at the AC21-A well using the empirical equation and the Biot-Gassman theory (BGT) with a consolidation parameter (equations 1 through 4), as outlined in Lee (2006c). 
S-wave velocities predicted using BGT along with measured SonicScope S-wave data at the WR313-H and S-wave velocities of reconstituted sediments are shown in figure $4 B$. As opposed to those shown in figure $4 A$, the BGT method predicts accurate $\mathrm{S}$-wave velocities of reconstituted sediments by Lee and others (2008) as well as those measured by SonicScope. Therefore, it is concluded that the $\mathrm{S}$-wave velocities of unconsolidated shallow sediments can be optimally predicted using the BGT (equations 1-4) method as outlined in Lee (2006c).

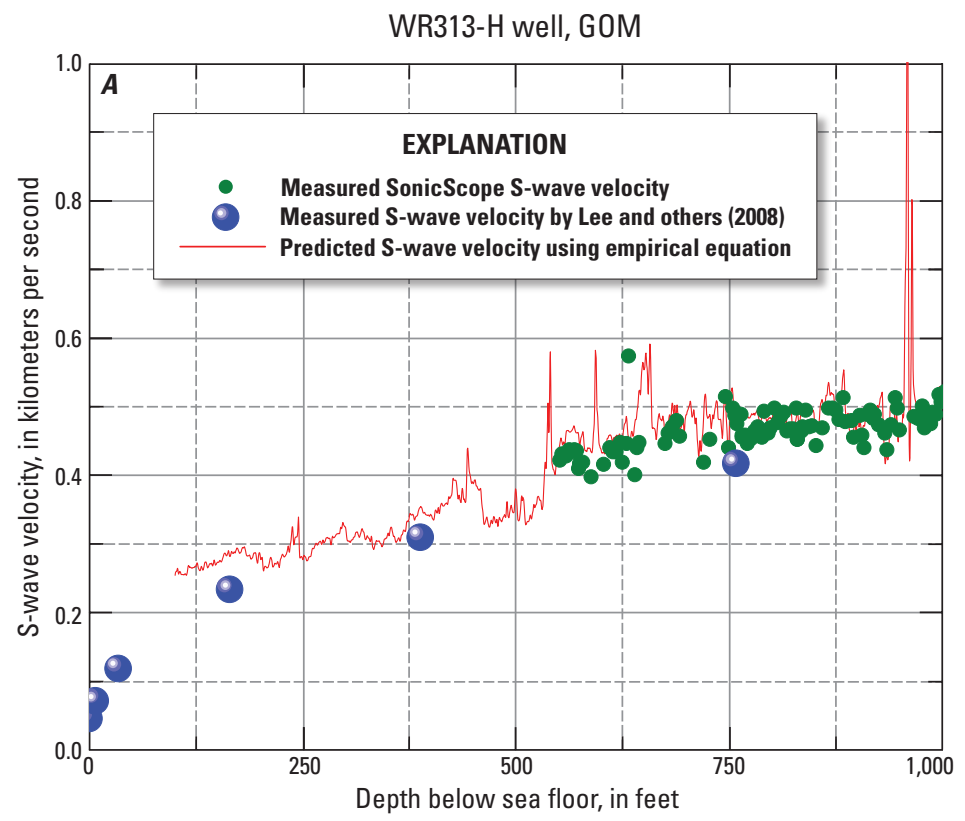

WR313-H well, GOM

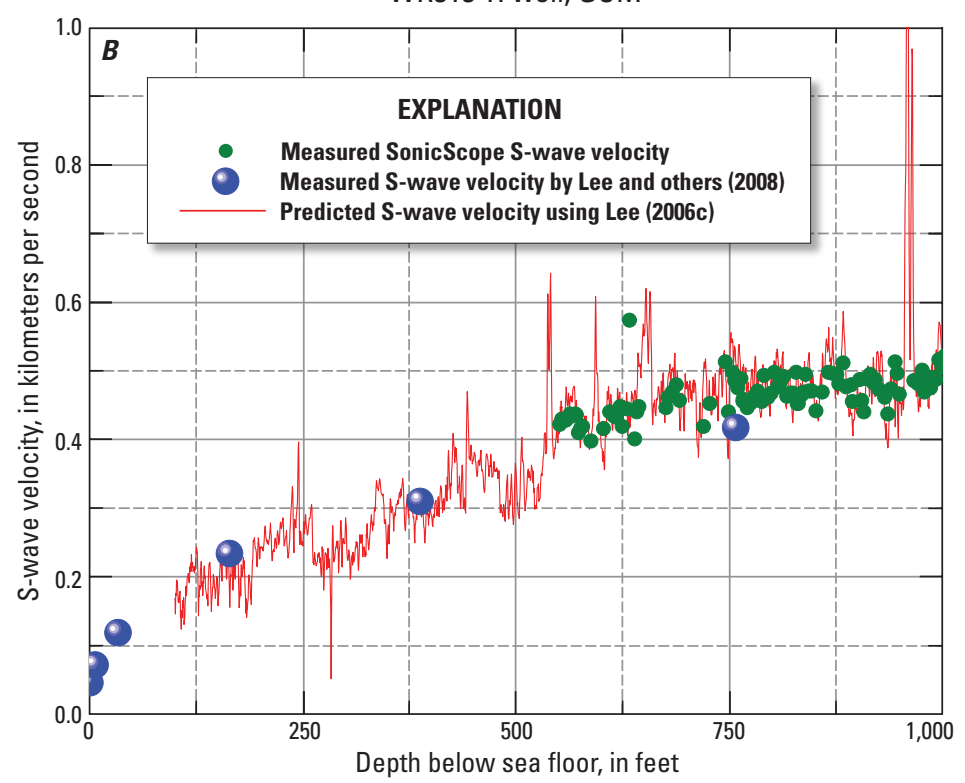

Figure 4. Predicted and measured SonicScope S-wave velocities at the WR313-H well, with S-wave velocities measured by Lee and others (2008) for the reconstituted sediment acquired at the Keathley Canyon 151-2 well (KC151-2). A, using the empirical equation derived from the six wells. $B$, using the Biot-Gassmann theory (BGT) with the consolidation parameter (equations 1-4) assuming that the pore space is saturated with water. 


\section{For Gas Hydrate-Bearing Sediments (GHBS)}

Numerous equations can be used to calculate P- and S-wave velocities of GHBS (for example; Helgerud and others, 1999; Jakobsen and others, 2000; Lee and Waite, 2008). In this paper, the simplified three-phase Biot-type equation (STBE) (Lee, 2008; Lee and Waite, 2008) is used to calculate the S-wave velocities of the GHBS. The difference between the WSS and GHBS in the framework of STBE is as follows: the first is the Kav shown in equation 2, and this term is changed into

$$
\frac{1}{K_{a v}}=\frac{\left(\beta_{p}-\phi\right)}{K_{s}}+\frac{\phi_{w}}{K_{w}}+\frac{\phi_{h}}{K_{h}}
$$

and the Biot coefficients, $\beta_{p}$ and $\beta_{s}$ in equation 4 , are expressed using the apparent porosity $\phi_{a s}$ instead of porosity $\phi$, which is defined as

$$
\phi_{a s}=\phi_{w}+\varepsilon \phi_{h}
$$

where
$\mathrm{K}_{\mathrm{h}}$ is the bulk modulus of the pure gas hydrate, $\mathrm{S}_{\mathrm{h}}$ is the gas hydrate saturation, $\phi_{w}=\left(1-S_{h}\right) \phi$, and $\phi_{h}=S_{h} \phi$.

Lee and Waite (2008) recommended using $\varepsilon=0.12$ to model GHBS. Also the effect of gas hydrate on the bulk density should be accounted for and is given by:

$$
\rho_{b}=\rho_{s}(1-\phi)+\rho_{w} \phi\left(1-S_{h}\right)+\rho_{h} \phi S_{h}
$$

where $\rho_{h}$ is the density of gas hydrate.

To predict S-wave velocities of GHBS, the gas hydrate saturations estimated from the P-wave velocities are explicitly inserted into the velocity equation, along with an appropriate consolidation parameter. When predicting S-wave velocities from the P-wave velocity and porosity for WSS, the consolidation parameter $\alpha$ is estimated at each data point (Lee, 2006c). From these estimated values of $\alpha$ with depth, a depth-dependent consolidation parameter can be derived. Figure 5 shows the gas hydrate saturation estimated from the P-wave velocity at the GC955-H well, using $\alpha=50(1000 / d)^{1}$, where $d$ is the depth in feet below sea floor.
GC955-H well, GOM

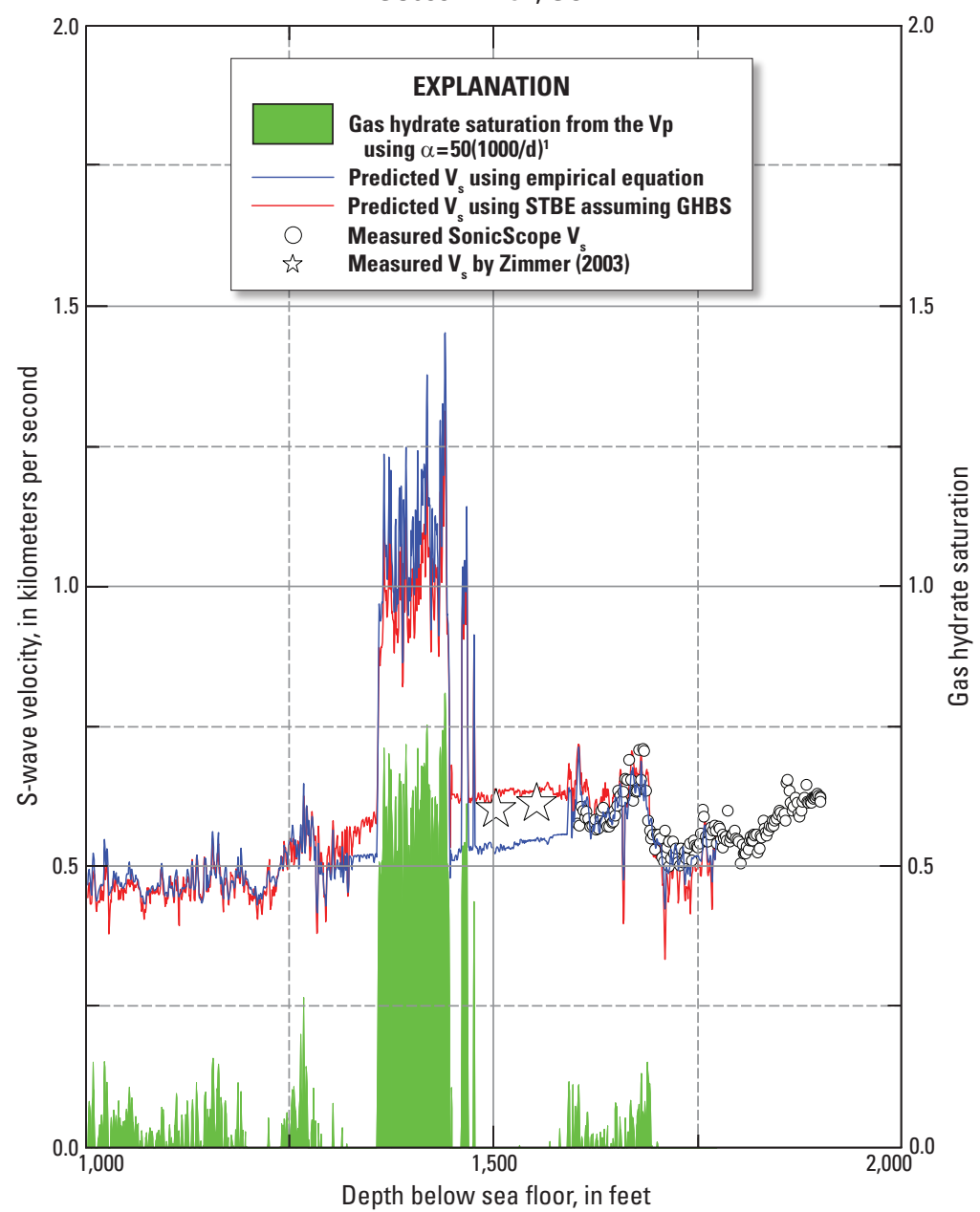

Figure 5. Predicted and measured SonicScope $\mathrm{S}$-wave velocities at the $\mathrm{GC} 955-\mathrm{H}$ well with gas hydrate saturations estimated from the P-wave velocity. S-wave velocity predicted using the simplified three-phase Biot-type equation (STBE), assuming that the pore space is saturated with gas hydrate (GHBS), is shown in red, and that predicted from the empirical equation $\left(V_{s}=0.59 V_{p}-0.6\right)$ is shown in blue; $V_{p^{\prime}}$ $\mathrm{P}$-wave velocity; $V_{s^{\prime}} S$-wave velocity. 
Figure 5 also shows the S-wave velocities predicted assuming that the measured $\mathrm{P}$-wave velocities are those for GHBS (for depths between 1,355 and 1,443 fbsf) using STBE at GC955-H well. The S-wave velocities of GHBS are calculated with $\alpha=50(1000 / d)^{1}$, which is the same parameter used to estimate gas hydrate saturation. For comparison, $\mathrm{S}$-wave velocities predicted using the empirical relation (equation 5) are also shown in figure 5. The average S-wave velocity predicted using the empirical equation for depths between 1,355 and $1,443 \mathrm{fbsf}$ is $1.081 \pm 0.124 \mathrm{~km} / \mathrm{s}$, whereas it is $0.999 \pm 0.100 \mathrm{~km} / \mathrm{s}$ when using STBE. Thus, the S-wave velocities of GHBS predicted from the empirical formula are slightly higher than those predicted from the BGT.

\section{Results and Discussion}

\section{S-wave Velocity for Sands}

The empirical relation shown in equation 5 was derived from S-wave data for clay-bearing sediments. Because severe washouts occurred for sands without gas hydrate in the pore space (Boswell and others, 2009), density porosity and the $\mathrm{P}$-wave velocity were severely affected and S-wave velocities were not measured at all. Figure 6 shows the measured and modified porosity (fig. $6 A$ ) and P-wave velocity (fig. $6 B$ ). The erroneous porosities inside large washout zones were substituted by calculated porosity using a sand-shale porosity
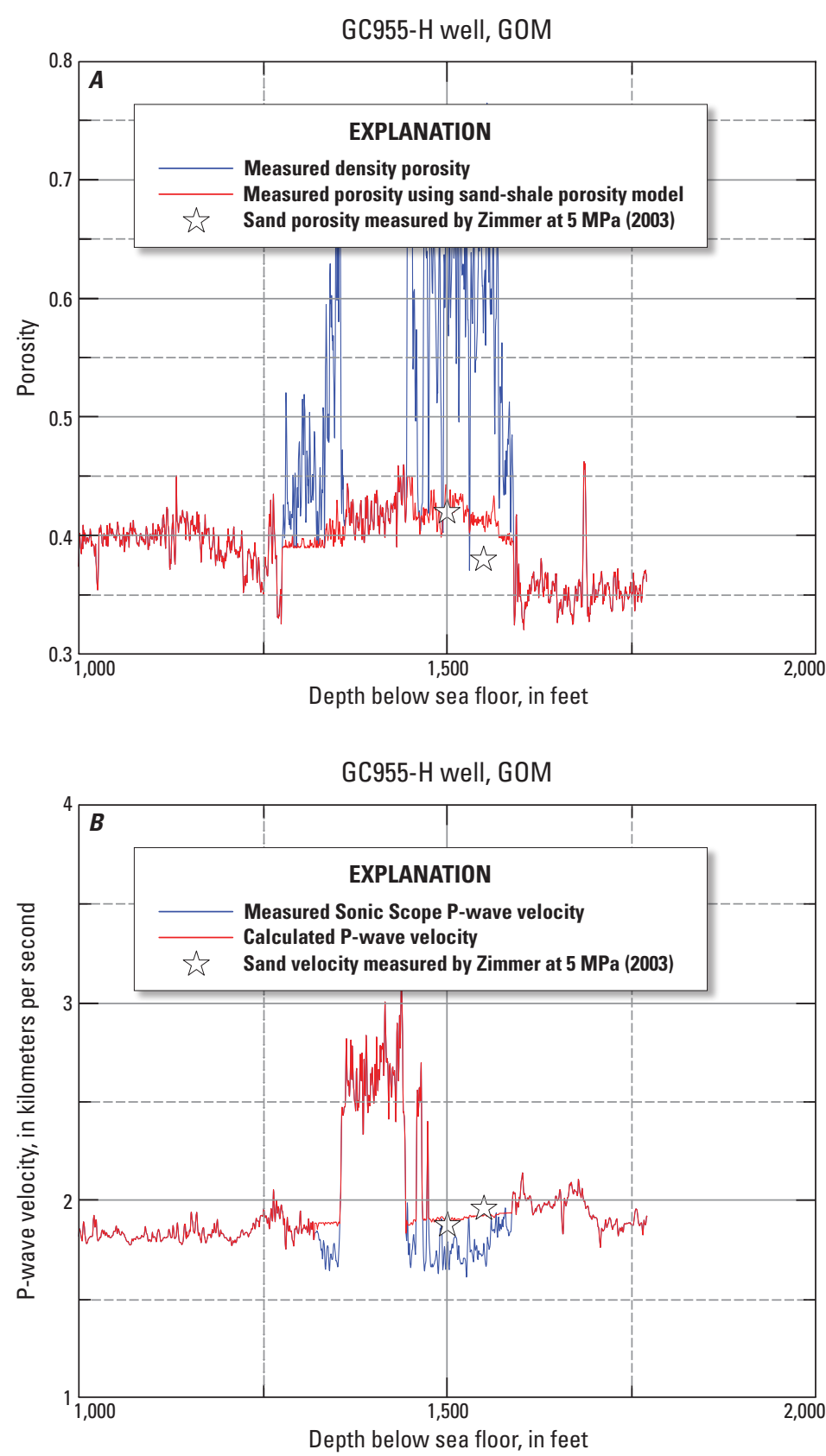

Figure 6. Measured and modified porosity and P-wave velocity at the GC955-H well. $A$, density porosity. $B$, P-wave velocity. MPa; megaPascal. 
model by Kolterman and Gorelick (1995). The P-wave velocities inside the washout intervals were replaced by calculated $\mathrm{P}$-wave velocity using the modified porosity shown in figure $6 A$ with the consolidation parameter $\alpha=50(1000 / d)^{1}$. This parameter is the same one used for the prediction of S-wave velocity mentioned previously and assumes that the pore space is saturated with water except for depths between 1,355 and $1,443 \mathrm{fbsf}$, where gas hydrates are present.

There are no independent measurements to test the accuracy of the modified porosity and the calculated P-wave velocity of sands at this well. Zimmer (2003) measured porosity and velocities for reconstituted sands from the GOM and Galveston, GOM, at various effective pressures. At the effective pressure of $5 \mathrm{MPa}$, the average porosity, the P-wave velocity, and the S-wave velocity are $0.42,1.874 \mathrm{~km} / \mathrm{s}$, and $0.602 \mathrm{~km} / \mathrm{s}$, respectively for Galveston sands and $0.38,1.957 \mathrm{~km} / \mathrm{s}$, and $0.62 \mathrm{~km} / \mathrm{s}$, respectively for GOM sands. Assuming that the depth of $1,500 \mathrm{ft}$ corresponds to an effective pressure of about $5 \mathrm{MPa}$, these values were plotted in figure 6 as stars (for visual effect, data for Galveston sand were plotted at 1,500 ft and $1,550 \mathrm{ft}$ for GOM sand). When the S-wave velocities measured by Zimmer (2003) are compared, figure 6 indicates that the modified porosity and calculated P-wave velocity using the modified porosity appear to be more accurate than measured values for sands at the GC955-H well.

Figure 5 shows predicted $\mathrm{S}$-wave velocities using the empirical equation and the STBE by explicitly inserting the gas hydrate saturations into the equation. When there is no gas hydrate in the pore space, the predicted velocity from the STBE is the same as that from the BGT. The predicted S-wave velocities of sands at depths near 1,500 fbsf from the empirical relation are less than those predicted from the STBE, although velocities of the clay-bearing sediments near 1,700 fbsf are almost the same as the STBE. The predicted S-wave velocities from the STBE are similar to those measured by Zimmer (2003). This indicates that the empirical relation is not accurate for sands at the GC955- $\mathrm{H}$ well and requires another relation applicable to sands. However, the prediction based on the STBE works well for both clay-bearing sediments and sands by incorporating the effect of porosity and grains into the prediction.

\section{Moduli of Sediments}

Geomechanics was one of the primary areas of interest for the JIP Leg II project, and V $p$-VS data were intended to be used to model geomechanical properties of GHBS, including borehole-stability models (J. Howard, Conocophillips, written commun., 2010). Unfortunately, none of the S-wave velocities were measured for GHBS and water-saturated sands. Therefore, it was decided to use the predicted S-wave velocities to derive mechanical properties of the sediments.

The dynamic bulk and shear moduli can be calculated from the $\mathrm{P}$ - and $\mathrm{S}$-wave velocities using equation 1 as:

$$
k=\rho V_{p}^{2}-4 \rho V_{s}^{2} / 3
$$

Figure 7 shows the calculated bulk and shear moduli at GC955-H well using the P-wave velocity and predicted S-wave velocity using STBE (fig. 5). For comparison, moduli calculated from the measured SonicScope P- and S-wave data for clay-bearing sediments at depths greater than 1,600 fbsf are also shown. The bulk and shear moduli estimated from the predicted S-wave velocities agree well with those estimated from the measured SonicScope S-wave velocities for clay-bearing sediments. Judging from the accuracy of the predicted S-wave velocities shown in figure 5, it appears that the moduli of GHBS shown in figure 7 are reasonable. The shear modulus of water-saturated sand at about 1,500 fbsf is about 0.8 gigapascals $(\mathrm{GPa})$, whereas it is more than $2 \mathrm{GPa}$ for GHBS with a 64-percent gas hydrate saturation.

\section{Comparison with Other Methods}

The mudrock equation by Castagna and others (1985) was based on a variety of in-situ and laboratory measurements for clastic silicate rocks and is given by:

$$
V_{s}=\left(V_{p}-1.36\right) / 1.16
$$

The predicted S-wave velocities using equation 10 are shown in figure $8 A$ and compared with those using the empirical equation 5 . The average $\mathrm{S}$-wave velocity predicted using equations 5 and 10 are $0.539 \pm 0.089 \mathrm{~km} / \mathrm{s}$ and $0.475 \pm 0.100 \mathrm{~km} / \mathrm{s}$, respectively, whereas that of the measured S-wave velocity is $0.535 \pm 0.079 \mathrm{~km} / \mathrm{s}$. As noted by Wang (2000), the mudrock equation underestimates the $\mathrm{S}$-wave velocity, and the underestimation is about 10 percent for the SonicScope data in GOM.

Wang's equation is based on the Biot-Gassmann equation with empirically derived parameters and is given by the following equation for WSS:

$$
V_{s}^{2}=\left(0.4211+0.0061 K_{w}\right) V_{p}^{2}-1.1255 K_{w} / \rho_{b} .
$$

As long as the second term is less than the first term in equation 11 , the S-wave velocity can be predicted. Figure $8 A$ also shows the predicted S-wave velocities using equation 11. When the P-wave velocity is less than about $1.73 \mathrm{~km} / \mathrm{s}$ with porosity greater than about 0.4 , the second term becomes greater than the first term. Thus, the S-wave velocity cannot be predicted. The predicted S-wave velocity varies from about 0 to $0.75 \mathrm{~km} / \mathrm{s}$, and the Wang equation is not appropriate to use for the SonicScope data measured for shallow sediments in these areas.

Lee (2006b) proposed a method based on BGT with a correction term $\Delta V_{s}$, which is given by:

$$
\Delta V_{s}=0.1075+0.0473 e^{-p / 8.623} \mathrm{~km} / \mathrm{s}
$$


where $p$ is the effective pressure in MPa. Figure $8 B$ shows the predicted S-wave velocities using Lee (2006b), which are compared to velocities predicted using the method shown in Lee $(2006 c, 2010)$. As can be seen from figure $8 B$, Lee (2006b) underestimated the S-wave velocity, and the underestimation increases as the S-wave velocity decreases. The average S-wave velocity using Lee (2006b) is $0.516 \pm 0.122 \mathrm{~km} / \mathrm{s}$, which is about a 4-percent underestimation. However, at shallow depths of about
$200 \mathrm{fbsf}$, the S-wave velocities predicted using BGT with a correction term (Lee, 2006b) differ more than 100 percent of the predicted S-wave velocity using BGT with a consolidation parameter (Lee, 2006c, 2010). Because equation 12 is based on the velocities of consolidated sands and tested for velocities of unconsolidated sediments at the effective pressure greater than about $10 \mathrm{MPa}$, the correction term may not be accurate for the shallow unconsolidated sediments in the GOM.

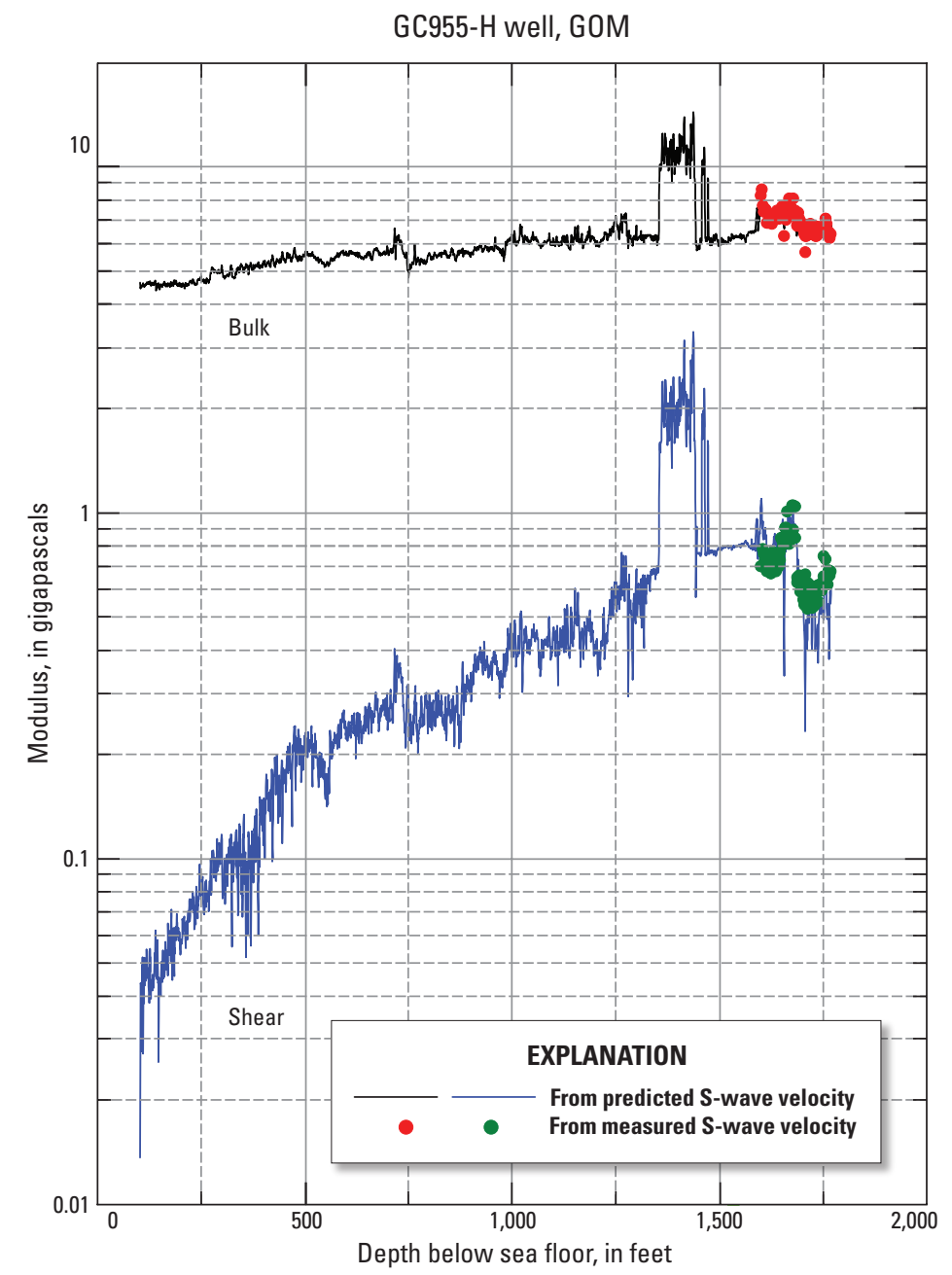

Figure 7. Estimated bulk and shear moduli of sediments at the GC995-H well. 

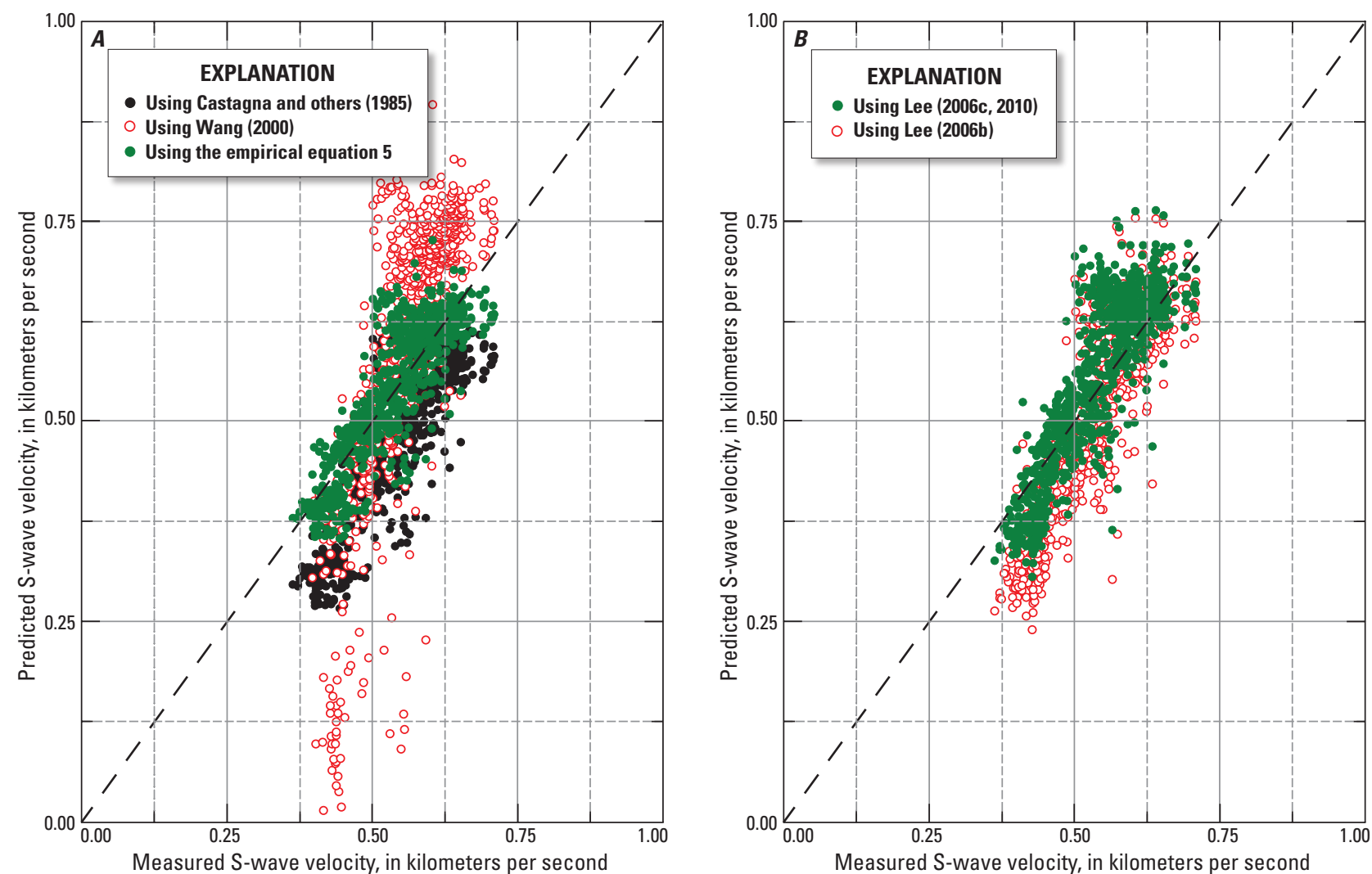

Figure 8. Comparisons of predicted and measured SonicScope S-wave velocities in the Gulf of Mexico. $A$, using empirical equations. $B$, using the Biot-Gassman theory with a correction factor for shear wave velocity.

\section{Summary and Conclusions}

The S-wave velocities of water-saturated sediments predicted using the Biot-Gassmann theory (BGT) with a consolidation parameter are as good as those predicted using the empirical equation derived from the six wells in the Gulf of Mexico (GOM). Furthermore, the prediction based on the BGT is preferable to the empirical equation to predict $\mathrm{S}$-wave velocities at very shallow depths. The empirical equation works well for clay-bearing sediments at these sites, but it appears to underestimate S-wave velocity for sands. However, the prediction of S-wave velocity based on the BGT works well for both sand and clay-bearing sediments. Although empirical equations are easy to apply, there is no guarantee that the empirical equations are accurate for a particular area because parameters of the empirical equation generally depend on the local sediment properties. Because the prediction method based on the BGT uses the measured P-wave velocity with porosity, however, it can be used in other areas as demonstrated in the GOM.

Another advantage of the BGT-based method is its ability to predict the S-wave velocities for gas hydratebearing sediment. By explicitly inserting gas hydrate saturations estimated from the P-wave velocity into a rock physics model based on the BGT, accurate $\mathrm{S}$-wave velocities can be predicted. It is demonstrated that the predicted S-wave velocity from the simplified three-phase equation can be used to calculate reasonable bulk and shear moduli of the sediment in the absence of measured S-wave velocity.

\section{References}

Boswell, Ray, Collett, T.S., Frye, M., McConnell, D., Shedd, W., Dufrene, R., Godfriaus, P., Mrozewski, S., Guerin, G., and Cook, A., 2009, Gulf of Mexico Gas Hydrate Joint Industry Project Leg II: Technical summary-Proceedings of the Drilling and Scientific Results of the 2009 Gulf of Mexico Gas Hydrate Joint Industry Project Leg II, 28 p.

Castagna, J.P., Batzle, M.L, and Eastwood, R.L, 1985, Relationship between compressional wave and shear wave velocities in clastic silicate rocks: Geophysics, v. 50, p. 571-581.

Cheng, C.H., and Toksöz, M.N., 1979, Inversion of seismic velocities for pore aspect ratio spectrum of a rock: Journal of Geophysical Research, v. 84, p. 7,533-7,543.

Greenberg, M.L., and Castagna, J.P., 1992, Shear-wave velocity estimation in porous rocks: Theoretical formulation, preliminary verification and applications: Geophysical Prospecting, v. 40, p. 195-209. 
Guerin, Gilles, Cook, A., Mrozewski, S., Collett, T., and Boswell, R., 2009, Gulf of Mexico Gas Hydrate Joint Industry Project Leg II-Green Canyon 955 LWD operations and results: Proceedings of the Drilling and Scientific Results of the 2009 Gulf of Mexico Gas Hydrate Joint Industry Project Leg II, $29 \mathrm{p}$.

Han, D.H., Nur, A., and Morgan, D., 1986, Effects of porosity and clay content on wave velocities in sandstone: Geophysics, v. 51, p. 2,093-2,107.

Helgerud, M.B., Dvorkin, J., Nur, A., Sakai, A., and Collett, T., 1999, Elastic-wave velocity in marine sediments with gas hydrates -Effective medium modeling: Geophysical Research Letters, v. 26, p. 2,021-2,024.

Hutchinson, D.R., Boswell, R., Collett, T.S., Dai, J., Dugan, B., Frye, M., Jones, E., McConnell, D., Rose, K., Ruppel, C., Shedd, W., Shelander, D., Wood, W., 2009, Gulf of Mexico Gas Hydrate Joint Industry Project Leg II-Walk Ridge 313 site selection: Proceedings of the Drilling and Scientific Results of the 2009 Gulf of Mexico Gas Hydrate Joint Industry Project Leg II, 35 p.

Jakobsen, M., Hudson, J.A., Minshull, T.A., and Singh, S.C., 2000, Elastic properties of hydrate-bearing sediments using effective medium theory: Journal of Geophysical Research, v. 105 , p. $561-577$.

Jørstad, A., Mukerji, T., and Mavko, G., 1999, Modelbased shear-wave velocity estimation versus empirical regressions: Geophysical Prospecting, v. 47, p. 785-797.

Kolterman, C.E., and Gorelick, S., 1995, Fractional packing model for hydraulic conductivity derived from sediment mixtures: Water Resources Research, v. 31, p. 3283-3297.

Kuster, G.T., and Toksöz, M.N., 1974, Velocity and attenuation of seismic waves in two-media: Part I. Theoretical considerations: Geophysics, v. 39, p. 587-606.

Lee, J.Y., Santamarina, J.C., and Ruppel, C., 2008, Mechanical and electromagnetic properties of northern Gulf of Mexico sediments with and without hydrates: Marine and Petroleum Geology, v. 25, p. 884-895.

Lee, M.W., 2005, Proposed moduli of dry rock and their application to predicting elastic velocities of sandstones: U.S. Geological Survey Scientific Investigations Report 2005-5119, 14 p.

Lee, M.W., 2006a, Inversion of elastic impedance for unconsolidated sediments: U.S. Geological Survey Scientific Investigations Report 2006-5081, 14 p.

Lee, M.W., 2006b, Explicit use of the Biot coefficient in predicting shear-wave velocity: Geophysical Prospecting, v. 54, p. $177-185$.

Lee, M.W., 2006c, A simple method of predicting S-wave velocity: Geophysics, v. 71, no. 6, p. F161-F164.
Lee, M.W., 2008, Models for gas hydrate-bearing sediments inferred from hydraulic permeability and elastic velocities: U.S. Geological Survey Scientific Investigations Report 2008-5219, 15 p.

Lee, M.W., 2010, Predicting S-wave velocities for unconsolidated sediments at low effective pressure: U.S. Geological Survey Scientific Investigations Report 2010-5138, 13 p.

Lee, M.W., and Waite, W.F., 2008, Estimating pore-space gas hydrate saturations from well-log acoustic data: Geochemistry, Geophysics, Geosystems, v. 9, Q07008, doi:10,1029/2008GC002081, 8 p.

Mrozewski, Stefan, Guerin, G., Cook, A., Collett, T., Boswell, R., 2009, Gulf of Mexico Gas Hydrate Joint Industry Project Leg II—LWD Method: National Energy Technology Laboratory, Proceedings of the Drilling and Scientific Results of the 2009 Gulf of Mexico Gas Hydrate Joint Industry Project Leg II, $9 \mathrm{p}$.

Pride, S.R., 2005, Relationship between seismic and hydrological properties, in Rubin, Y., and Hubbard, S., eds., Hydrogeophysics: New York, Kluwer Academy, p. 217-255.

Shedd, W., Hutchinson, D., Boswell, R., Collett, T., Dai, J., Dugan, B., Frye, M., Jones, E., McConnell, D., Rose, K., Ruppel, C., Shelander, D., and Wood, W., 2009, Gulf of Mexico Gas Hydrate Joint Industry Project Leg II-East Breaks 991 and Alaminos Canyon 21 site selection: Proceedings of the Drilling and Scientific Results of the 2009 Gulf of Mexico Gas Hydrate Joint Industry Project Leg II, 18 p.

Wang, Z., 2000, Velocity relationships in granular rocks, in Wang, Z. and Nur, A., eds., Seismic and acoustic velocities in reservoir rocks, Recent development: Society of Exploration Geophysics, v. 3, p. 377-383.

Xu, Shiyu, and White, R.E., 1996, A physical model for shear-wave velocity prediction: Geophysical Prospecting, v. 44 , p. $687-717$.

Yun, T.S., Narsilio, G.A., Santamarina, J.C., 2006, Physical characterization of core samples recovered from Gulf of Mexico: Marine and Petroleum Geology, v. 23, p. 893-900.

Zimmer, M.A., 2003, Seismic velocities in unconsolidated sands - Measurements of pressure, sorting, and compaction effects: Doctoral Thesis, Stanford, Palo Alto, California, 204 p. 
Publishing support provided by:

Denver Publishing Service Center

For more information concerning this publication, contact: Center Director, USGS Central Energy Resources Science Center Box 25046, Mail Stop 939

Denver, CO 80225

(303) 236-1647

Or visit the Central Energy Resources Science Center Web site at: http://energy.usgs.gov/ 


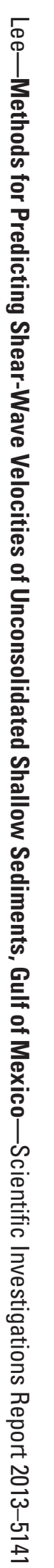

